\title{
Carat of Gold Alloy
}

National Cancer Institute

\section{Source}

National Cancer Institute. Carat of Gold Alloy. NCI Thesaurus. Code C69173.

A unit of measurement for the proportion of gold in an alloy, defining the purity of gold.

Pure gold is 24 carat, whilst 18 carat gold comprises $18 / 24$ gold and 6/24 alloy. 